\title{
The Observer Video-Pro: New software for the collection, management, and presentation of time-structured data from videotapes and digital media files
}

\author{
LUCAS P. J. J. NOLDUS, RUDIE J. H. TRIENES, \\ ANDRÉ H. M. HENDRIKSEN, HAN JANSEN, and ROLAND G. JANSEN \\ Noldus Information Technology, Wageningen, The Netherlands
}

\begin{abstract}
The Observer Video-Pro is a system for collecting, managing, analyzing, and presenting observational data. It integrates The Observer software with time code and multimedia hardware components. It extends the functionality of a conventional real-time event recording program in various ways. Observational data can be collected, reviewed, and edited with synchronized display of the corresponding video images. For optimal visual feedback during coding, one can display the video image in a window on the computer screen. Video playback from either a VCR or a digital media file can be controlled by the computer, allowing software-controlled jog, shuttle, and search functions. Besides a wide range of VCRs, The Observer Video-Pro supports all major digital video file formats. The software allows the user to summarize research findings in numerical, graphical, or multimedia format. One can create a time-event plot for a quick glance at the temporal structure of the observed process, or run specific analysis procedures and generate reports with statistics. An Event Summary function is available for exploratory and qualitative analysis. Video material can be summarized in a Vidco Play List, which allows on-screen summary presentations or the creation of highlight compilations on tape, $\mathrm{CD}$, or other media. Video images can be captured and saved as disk files, for use as illustrations in documents, slides for presentations, and so forth. In this paper we describe the design and operation of the system, illustrated with a case study from research on Repetitive Strain Injury (RSI).
\end{abstract}

Whereas narrative descriptions of behavioral data rely to a large extent on the individual observer recording them, the aim of systematic observation is for properly trained observers to produce identical protocols, given that they observed the same stream of behavior. It is primarily this urge for reproducibility that grants systematic observation the epithet scientific. One of the prominent characteristics of systematic observation is the use of predefined lists of behavioral codes, developed for a particular observational study (Lehner, 1996; Martin \& Bateson, 1993). These coding schemes are the instruments of measurement for observational research, since they specify which behavior is to be selected from the passing stream of events. As such, they guarantee standardized data, statistical analysis of which will yield quantifiable results.

The authors thank Aurelia Kwint, Rob Ottenhoff, Rick Elbers, Jessica Sweens, Roy van Boxtel, and Bart van Roekel for their invaluable contribution to the design; programming, and testing of the software. The authors are also grateful to Anabele Simoés, José Carvalhais, Florentino Serranheiro, Madalena Magalhães, and Carlos Fujāo of the Department of Ergonomics, University of Lisbon (Lisbon, Portugal), who kindly put their research design, data, and video files at our disposal. Correspondence should be addressed to L. P. J. J. Noldus, Noldus Information Technology b.v., P.O. Box 268, 6700 AG Wageningen, The Netherlands (e-mail: I.noldus@noldus.nl; URL: http://www.noldus.com).

Note: The authors have a direct financial interest in the product described in this paper-Editor
The decreasing cost and widespread availability of computers have stimulated the development of tools for computer-aided behavioral observation. During the past decade, several such systems have been described in the literature (for reviews, see Donát, 1991; Farrell, 1991; Horner \& Storey, 1989; Kahng \& Iwata, 1998; Noldus, van de Loo, \& Timmers, 1989). These systems facilitate the task of observation by offering direct data entry into a computer, with automatic time stamping based on the internal clock. This eliminates time-consuming and error-prone data transcription from paper and increases the efficiency of data analysis and graphing.

\section{The Observer}

Development history. Since the late 1980s, our group has been involved with the development, deployment, and support of an observational data collection and analysis package named "The Observer." The first commercial edition (Version 2.0) was described in this journal by Noldus (1991). The program quickly found its way into a variety of research disciplines (Albonetti et al., 1992; Boccia, 1992; Davis, 1993; Lazarus, 1994; Tourtellot, 1992; Visser, 1993; Wawra, 1994). For mobile data collection away from the PC, special versions for handheld computers were developed (Hile, 1991). Originally a DOS application, versions of The Observer for Windows and Macintosh have subsequently become available. 
Live observations. The original program-like most other available software-only supported "live" observations, which limited its use to relatively simple behavioral processes. As any behavioral researcher knows, the number of events that can be scored accurately by a single observer in real time is very limited. Since there is no permanent record of the observation, data cannot be validated and checked for reliability. Furthermore, the presence of the observer may disturb the subjects under observation.

Videotape. For this reason, behavioral researchers often start with recording a process on videotape, after which observational data are collected during playback of the tape. By interfacing the VCR to the computer and using computer-readable time code on the tape, event timing at single-frame (or even single-field) accuracy becomes possible, independent of the playback speed of the VCR. This technology is supported by several computerized tools for coding and annotating videotapes (Sanderson et al., 1994; Tapp \& Walden, 1993; van der Vlugt, Kruk, van Erp, \& Geuze, 1992), and The Observer has had this facility since 1994 (Baber, 1994; Boccia, 1995; Keene, 1994).

Digital video. The systems described were designed for use with analog videotape. During the past few years, however, digital videotape is becoming increasingly popular. Digital tapes, in comparison with their analog predecessors, offer higher picture quality and allow copying without any loss of quality. Besides the gradual replacement of analog VCRs by digital decks, there is a trend toward storage of video on disk in digital media files. Unlike tapes, with their inherent sequential access, disk media such as a hard drive or CD offer direct random access. As a result, digital video files allow for extremely fast searching and reviewing, which makes systems highly interactive.

The Observer Video-Pro. In order to make these new technological developments applicable in observational research, and to be prepared for future developments in the realm of multimedia, we developed The Observer Video-Pro. This system is presented as an integrated system for collection, management, and analysis of timestructured data from live observations, analog or digital videotapes, and digital media files. In this paper we describe the design and operation of the system.

Case study. To illustrate the methodology of detailed video analysis and its inherent advantages when it comes to studying complex and rapid behaviors, we will present a case study from research on repetitive strain injury (RSI). The case study concerns an experimental setup designed for systematic observation of movements of wrist, elbow, and shoulder joints that are liable to cause RSI. The setup was developed by researchers at the Department of Ergonomics, University of Lisbon, in collaboration with the second author. The subjects under observation were workers in a car assembly plant, for hours on end performing cyclic production tasks, every task lasting on average $11 \mathrm{sec}$. Some characteristics of RSI make systematic observation and analysis of video mate- rial an appropriate research method. First, among the main causes for RSI is the high frequency of repetition of particular movements (McPhee, 1992). These movements can easily be detected through frame-by-frame observation of video files. Second, the deleterious effect of these movements is cumulative; that is, the duration of the repetitive movements contributes to a certain extent to the scale of the disorder (Putz-Anderson, 1992; Rempel, Harrison, \& Barnhart, 1992). The duration of various types of repetitive movements during a single task can be readily calculated with data files resulting from detailed coding of video recordings. Third, the workload during these repetitive movements is also an important factor contributing to RSI. In the experimental design, we have taken these three characteristics (frequency, duration, and workload) into account.

\section{Software and Hardware Specifications}

Software. The Observer Video-Pro is an integrated system, comprising various software and hardware components. The software consists of the Base Package for Windows and the Support Package for Video Analysis. The Base Package includes software functions to design research projects, create observational coding schemes, collect "live" observational data, manage data files, and perform data analysis. The Support Package adds to this the functionality to collect, review, edit, and summarize observational data from analog and digital videotapes and digital media files. The software has been written in 32 bit object-oriented $\mathrm{C}++$, using Microsoft Visual Studio 6.0 with MFC and DirectX libraries. The code has been optimized for Windows 95 and later, NT 4 (Service Pack 3), and Windows 2000.

Analog or digital videotape. In addition to the software, The Observer Video-Pro consists of several hardware components, the exact configuration of which varies with the application. A typical setup for use with analog or digital tape (Figure 1A) includes a professional videocassette recorder with built-in RS-232 interface allowing the VCR to be controlled by the computer, a time code generator and reader, and a video overlay board to display the video image in a window on the computer screen. The time code generator is either built into a VCR, a camcorder, or a stand-alone unit. The time code reader is either a plug-in board or an external unit. The latter allows a notebook computer to be used as a video analysis station. The PC should have at least a $133-\mathrm{MHz}$ Pentium processor, $32 \mathrm{MB}$ of RAM, and $25 \mathrm{MB}$ of free hard disk space. The software supports a wide range of professional analog and digital VCRs, tape controllers, and time code readers.

Digital video on disk. For use with digital video on disk (Figure 1B), one only needs a video capture board (e.g., an MPEG encoder), which digitizes the output of the video source (camera, VCR) and streams it to a file on the computer's hard disk. With a $200-\mathrm{MHz}$ or faster processor, 16-bit color display, and Microsoft DirectShow (successor of Video for Windows and ActiveMovie) installed, software-based playback of video files at full 

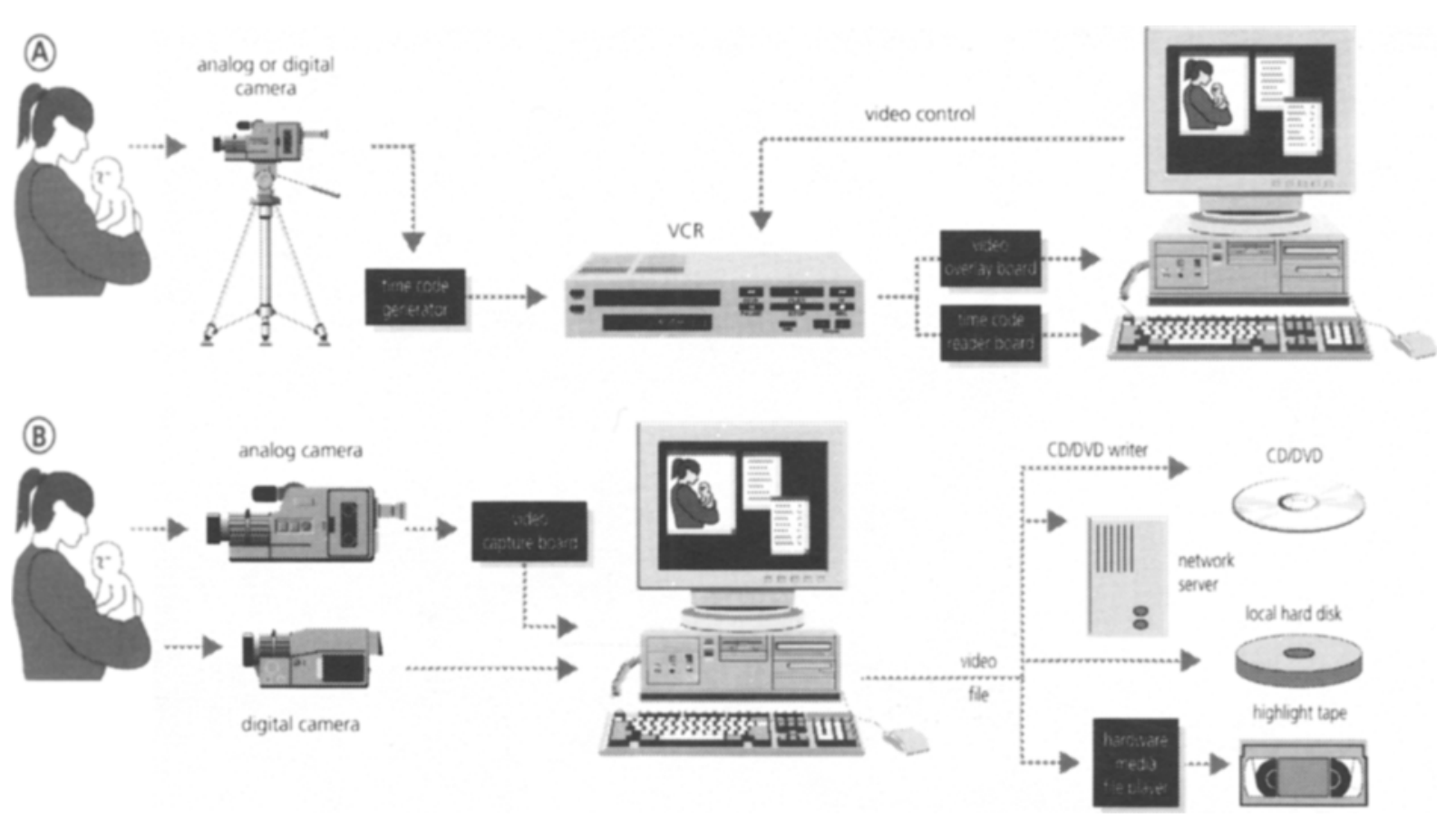

Figure 1. The Observer Video-Pro: Schematic representation of hardware components. (A) System with videotape. During filming, or while copying a tape from a camcorder to a stationary VCR, the time code generator adds an invisible time code to each video frame. During a coding session, the time code reader retrieves the time code from the tape and passes it on to the PC for event timing. The video overlay board displays the video signal in a window on the computer screen. The computer controls the playback of the VCR. (B) System with digital video on disk. If an analog camera is used, the video capture board digitizes the video signal, resulting in a digital media file on disk. With a digital camera, the DV output can be streamed directly to the computer's hard disk. During a coding session, the software calculates the time codes from the digital media file, which assures frame-accurate timing. Video files and observational data can be archived on optical or magnetic disks. A hardware media file player (e.g., MPEG decoder) with analog output can be added for smooth playback of the file to a video monitor or VCR, or for the production of highlight tapes.

frame rate and resolution is possible. Alternatively, a hardware decoder can be installed. These boards often also provide analog output, which allows video clips to be copied back to videotape. Finally, high-capacity storage devices such as a zip drive, CD writer, or DVD recorder can be used to archive and retrieve digital media files. Such a setup requires a $\mathrm{PC}$ with at least a $133-\mathrm{MHz}$ Pentium processor, $32 \mathrm{MB}$ of RAM, and sufficient hard disk space for temporary storage of digital media files (e.g., $600 \mathrm{Mb}$ for approximately $1 \mathrm{~h}$ MPEG-1). Software support for all common digital video formats (AVI, QuickTime, MPEG1, MPEG-2, MPEG-4, DV, etc.) is available.

\section{Configuring the System}

Data collection during an observation session is governed by the experiment design laid out in the program (Figure 2). The sampling method we have used in the RSI study is focal sampling (Altmann, 1974): During a single observation we continuously observed and recorded all behaviors relevant to the research question. Behaviors can be defined as events or states that permit the computation of frequency as well as duration statistics. The Observer also supports instantaneous, one-zero, and ad lib sampling.

We defined several independent variables - that is, subject identifiers or contextual parameters that remain con- stant during a single observation, and that allow us to select particular data files for data analysis afterward. Examples of independent variables are name of operator, gender, age, location of observation, day of the week, and so on.

We defined a number of behaviors and assigned a key code to each behavior. These keys are pressed to record the occurrence of an event during an observation session. We divided all behaviors into separate classes, where each class holds a group of mutually exclusive and exhaustive behavioral elements. During analyses, the subdivision of behaviors into classes allows nested analysis - that is, calculation of statistical parameters of simultaneously occurring events. This way of scoring behaviors in separate classes offers the advantage of not having to restrict oneself a priori to a single research hypothesis. Instead, the data collected in this fashion can answer a plethora of questions that need not have been defined before the start of observation. In our RSI study, we could thus obtain answers to questions like the following: How many times did a wrist movement occur while the elbow was heavily flexed and the shoulder was abducted from the body? How long did a certain type of wrist movement occur while force was used or a tool was handled? What was the frequency of transitions of several types of wrist movements while tools were handled? The Observer allows the use of logical operators with which many other queries can be formulated. 


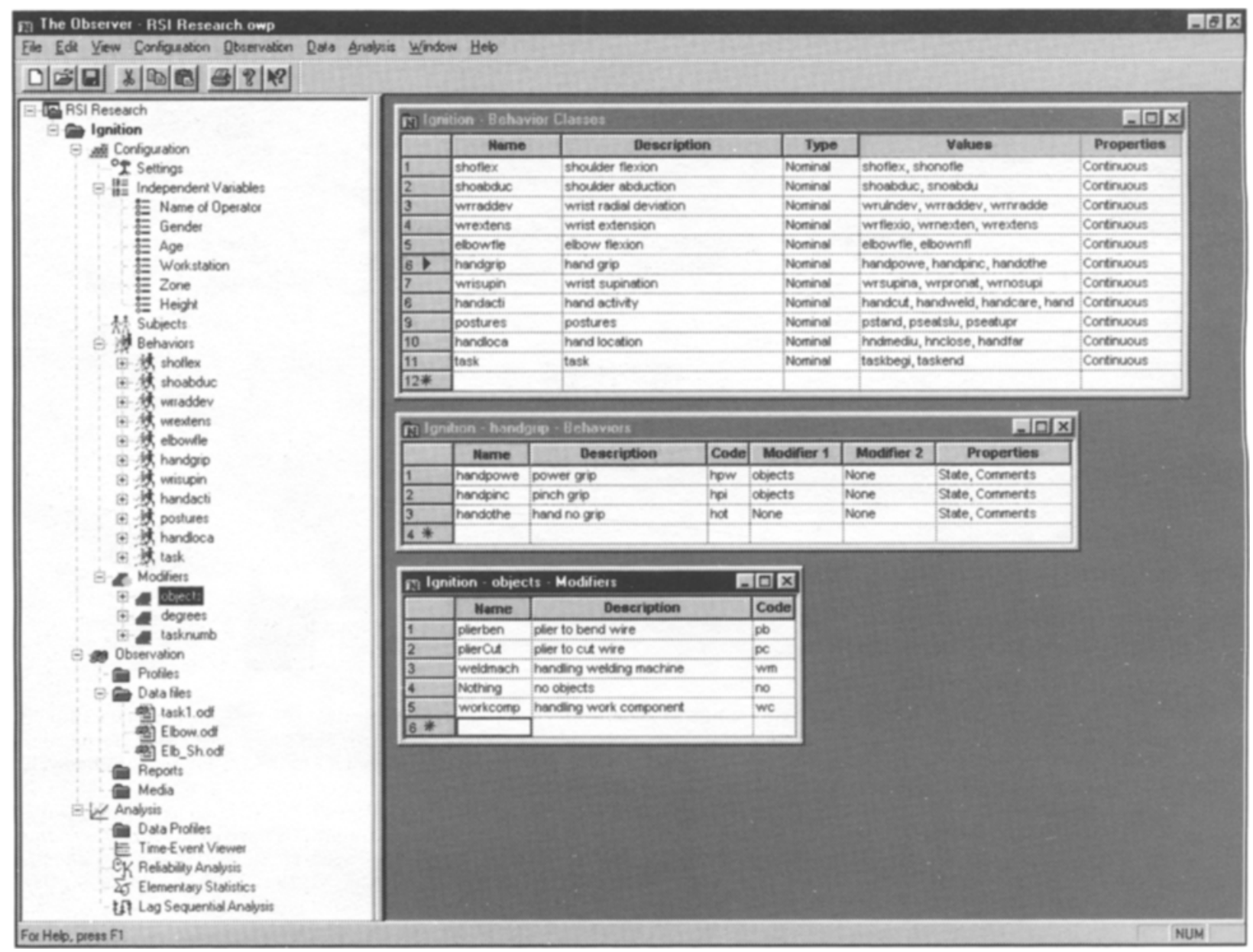

Figure 2. Screen of The Observer showing the structure of a project. The pane on the left shows the workspace "RSI research" as the highest level of organization. The workspace contains one project named "Ignition." The project is divided into Configuration, Observation, and Analysis, which represent the three stages in an observational study. The windows on the right show details of three items of the configuration: The 11 classes of behavioral elements, the elements in the class "handgrip," and the class of modifiers named "objects."

Finally, we defined a number of modifiers - that is, additional parameters that fine-tune the behaviors (e.g., the angle [in degrees] in which wrist, elbow, and shoulder joints are twisted; the type of tool handled, etc.). Besides behaviors and modifiers, The Observer also allows the use of actors - that is, the subject who performs a behavior. Actor codes are commonly used in studies of behavioral interaction and communication; we did not use them in this case study.

A detailed description of all behaviors and modifiers is provided in Appendix A.

\section{Event Recording}

Basis for event timing. Data collection with The Observer Video-Pro can be done in three modes. In a "live" setting, the internal computer clock, accurate to $1 / 18 \mathrm{sec}$, is used as the event timer. With data collection from (analog or digital) tape, a time code in each video frame allows event timing at $1 / 30$ (NTSC) or $1 / 25$ (PAL/SECAM) $\mathrm{sec}$ resolution. Certain time code generators and readers allow single-field precision (i.e., $1 / 60$ or $1 / 50 \mathrm{sec}$, respectively). The recommended time code generators produce vertical-interval time code (VITC), which can be read at different playback speeds and that leaves the two audio tracks available for other use (e.g., verbal comments). With data collection from digital media files, frame numbers in the file are used as the time basis. During operation, The Observer translates these numbers to hours, minutes, seconds, and fractions of seconds.

Observation procedure. Prior to actually starting an observation, the user has to enter a name for the data file. One can also select an existing data file with its associated video file to insert records into the data file, thereby making the data file increasingly detailed. Next, the user assigns a value to each of the independent variables predefined in the research design, positions the media file at the point where data collection should commence, and finally starts the observation. During data acquisition, actors, behaviors, and modifiers are scored by typing predefined key codes or clicking codes on the screen. At each valid key 


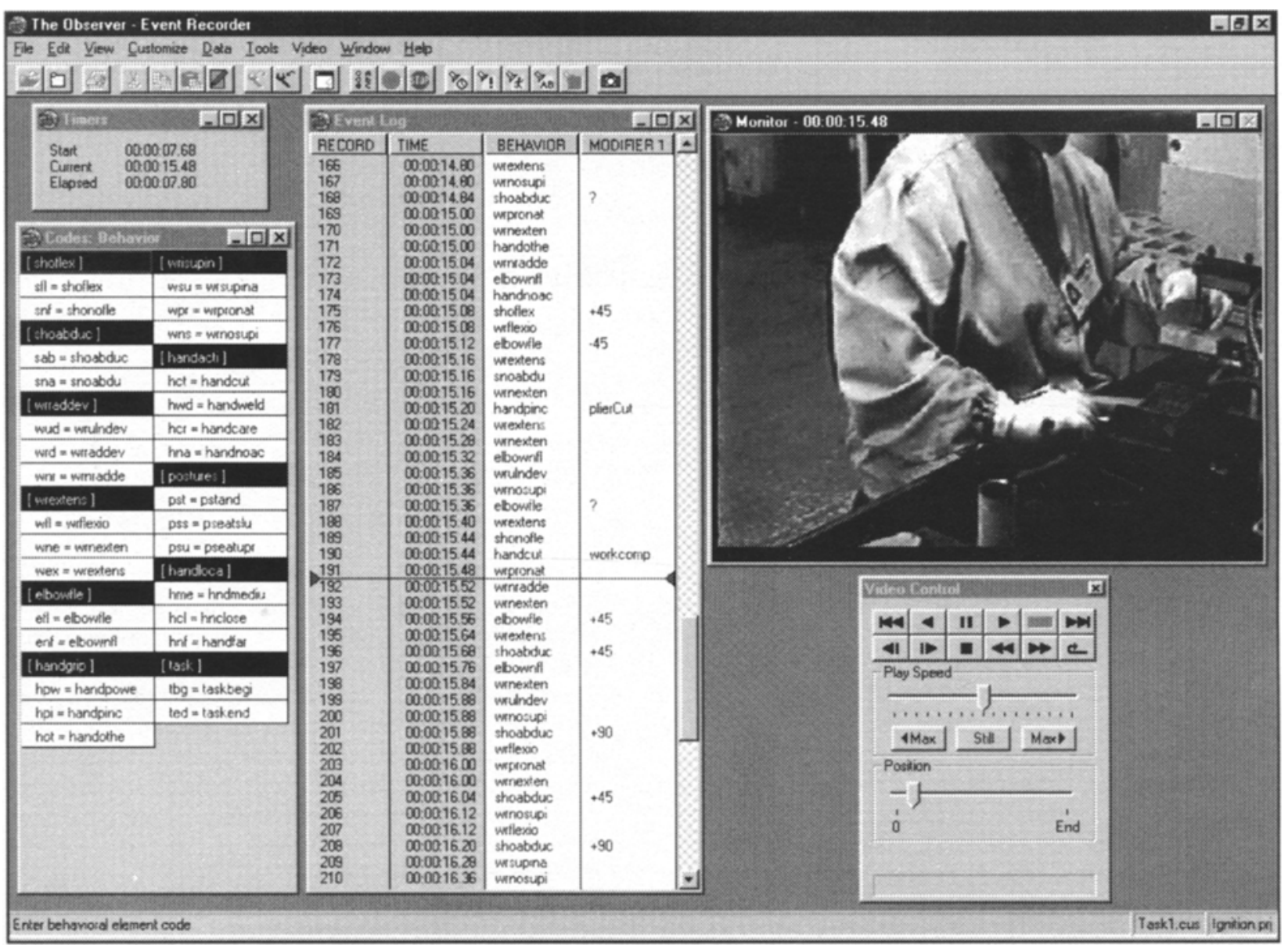

Figure 3. The main application window during an observation session. The Event Log window contains the chronological list of event strings, each with a record number, time stamp, behavior, and modifier. The horizontal cursor indicates the time that corresponds with the current position in the video file. The Monitor window displays the digital video file, with the current time in its title bar. The Codes window shows all predefined behavioral elements with their key codes, grouped in classes. The Video Control toolbox emulates the front panel of a VCR and allows the user to control the video display. The Timers window displays the start time of the observation, the current time of the video file, and the elapsed time of the observation. Please note that this screen is just one possible screen layout; presence, size, and position of each window are fully customizable. After the observation ends, the data file is saved, added to the current project, and made available for data analysis. For an example of an observational data file, see Appendix B.

press, the program calculates the elapsed time from the start of the observation and logs the time-stamped event record in the observational data file (Figure 3). If the user enters an undefined code, an alert message is displayed.

\section{Special Functions Available During an Observation Session}

To facilitate data entry, retrieval, and summarization, we have developed a number of special program functions. We will discuss a small selection below.

Free-format annotation. In addition to scoring predefined events, one can enter three types of free-format annotations in the data file. First, one can insert marker records with short notes attached. Second, for more extensive time-stamped notes, The Observer offers a special Notepad window. Third, one can enter comments for each record, as an extra column in the data set.
Video control. The playback of the videotape or file can be controlled via menu options, shortcut keys, or onscreen buttons. Play forward, play reverse, rewind, fast forward, pause, stop, frame-by-frame jog, and various shuttle speeds, both forward and reverse, are supported. Which options are actually implemented depends on the video source used. The Observer Video-Pro comes with built-in drivers for a wide range of VCRs and media file players. One can jump to any position in the digital video file using a position slider. A Quick Review option allows one to jump back a user-defined interval followed by slowmotion playback at user-defined speed, triggered by a single mouse click or key press.

Finding events and video images. The user can search for a specific time stamp, event, marker, or text string in the data file (Figure 4). Provided that the computer controls the video source (tape or file), the corre- 


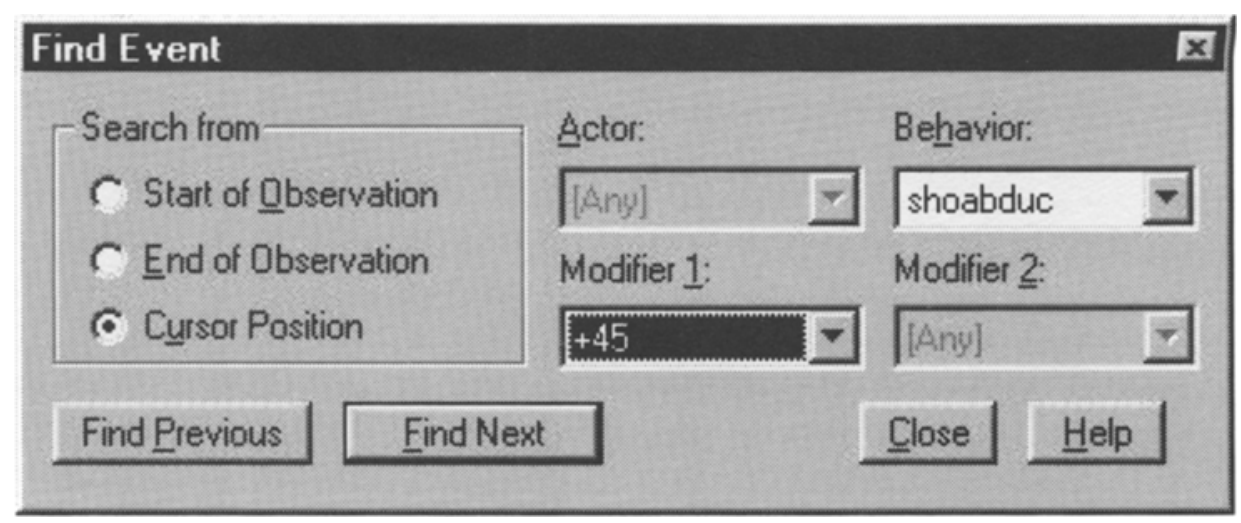

Figure 4. The Find Event dialog box. The Actor, Behavior, Modifier 1, and Modifier 2 drop-down list boxes hold all predefined actors, behaviors, and modifiers. Finding a specific event will also display the corresponding video image.

sponding video frame will be displayed as well. One can also define a "roll-on interval" to see the events that led up to the event that was searched for. A search operation on tape may last seconds to minutes, but access to a particular event and corresponding video frame in a digital media file is virtually instantaneous.

Video play list. In a typical observational study, comprising many hours of video recording, one rarely replays all video footage when presenting one's findings. Rather, one shows a few short clips to illustrate the most significant results. Creating a video compilation manually can be a very time-consuming operation, which is why only few people make use of this technique as part of scientific presentations. One can use special video editing systems for this purpose, but these are often complex to use and offer a lot of functionality beyond what is needed by the behavioral researcher. To resolve this, The $\mathrm{Ob}$ server Video-Pro allows the user to create a Video Play List, a series of video episodes placed in a user-defined order for playback. The user creates this list by simply dragging records from the event log to the Video Play List, after which sequence, duration, and other properties of the clips can be modified. The episodes can be played on screen (or sent to a computer projector) or copied to a compilation videotape or $\mathrm{CD}$. Single video images can also be captured and saved as disk files, for use as illustrations in documents, slides for presentations, and so on.

Event Summary. For applications where an accurate numerical analysis is not required, The Observer offers an Event Summary. This is a table with a user-defined selection of events from one or more data files. Events can be edited, comments can be added, and records can be ordered using various sort keys. This tool is especially useful for qualitative and exploratory analysis of selections of one or more data files. The results can be printed with a header and footer, or saved in a file.

\section{Data Analysis}

Data filtering. Before subjecting data to a specific analysis, one can filter observational data at several hierarchical levels. The following filters are available:
- Observations. One can select one or more observational data files from a project. Files can be selected manually or based on values of independent variables (e.g., all files for which sex $=$ male).

- Time window. The time window refers to the section of the data file to be included in the analysis. Start and end criterion can be either time or event based (e.g., from time $=30$ to event $=$ John looks). One can also run an iterative analysis across multiple time intervals (e.g., 1-min blocks in a 30-min experiment).

- Nesting levels. Nesting levels are used to measure the co-occurrence of events and states in different classes. One can combine nesting conditions with boolean operators to form complex queries and answer questions like, "How often did the operator reach for a tool with his right hand while holding an object in his left hand?"

- Events. One can select the actors, behaviors, and modifiers for which statistics must be calculated. Each element in the data record (actor-behavior-modifier 1modifier2) can be replaced by a wild card, resulting in $2^{4}=64$ different selection filters.

Data analysis options. The Observer offers the following data analysis functions:

- The time-event table is a chronological listing of timestamped events, grouped in columns for each actor or class of behavioral elements.

- The time-event plot gives an impression of how events are spread in time and whether or not large variations in the duration of behaviors occur; observational data are plotted as traces against elapsed time.

- Reliability analysis calculates the level of agreement between pairs of data files, including Cohen's $\kappa$ and Pearson's $r$. This technique is especially useful for training new observers.

- The elementary statistics module computes descriptive measures for individual events or combinations of events, for single or multiple data files. Statistics include frequency of occurrence, latency, total duration, proportional duration, mean duration, standard deviation, standard error, minimum duration, and maximum duration. 
- The lag sequential analysis technique calculates the frequency of transition between pairs of events within a certain lag in a time series. For instance, in the RSI study we created a matrix with frequency of transitions between wrist deviation, wrist extension, and wrist supination. Transition probabilities are used to analyze the temporal structure of the observed process.

Analysis output files can be readily exported to most databases, spreadsheets, and statistics packages available on the market.

\section{Discussion}

Adding value to video. As Tapp and Walden (1993) have already pointed out, programs for coding behavioral data from video show similarities with tape-editing and list-management software in that they can control video sources and provide archival and retrieval of video clips. However, what makes video coding software designed for behavioral research unique is the fact that it adds genuine value to the video material by anchoring observational data to video frames, by validating entered data against coding schemes, and by tightly integrating data collection with numerical and graphical data analysis. The Observer Video-Pro extends this line by offering a platform for the support of current and future standards for analog and digital videotape as well as digital media files.

Future developments. Digital video transmission and storage is quickly becoming mainstream technology. In the near future, an IEEE 1394 ("Firewire") interface and over $10 \mathrm{~GB}$ of disk storage will be standard on new PCs, which will allow users to stream substantial lengths of video from a digital camcorder straight to the hard drive. It is our challenge to keep up with these developments by developing new software to allow researchers to exploit the vast potential of digital video for behavioral research. The specifications of The Observer Video-Pro in this paper were written in August 1999. However, the software is under continual development, and specifications will have changed by the time of publication. For instance, software drivers for M-JPEG disk recorders have recently been completed, and research into video access across local-area networks and the Internet is in progress. Please contact L.P.J.J.N. for the current software functionality as well as hardware and software requirements.

Availability. The Observer Video-Pro is commercially available from Noldus Information Technology and various international distributors. Readers can contact the the first author. to receive a CD with an evaluation version with sample data and video files.

\section{REFERENCES}

Albonetti, M. E., Lazarus, J., Dickins, D. W., Whybrow, A., Schönheiter, R., Prenter, J., Elwood, R., Newman, J. D., Ö́berg, F. O., Kaiser, L., Pham-Delègue, M. H., Verguelen, V.,
Fentress, J. C., \& BocCla, M. L. (1992). Software multiple review. The Observer: Software for behavioural research, Version 2.0. Ethology, Ecology, \& Evolution, 4, 401-414.

Altmann, J. (1974). Observational study of behavior: Sampling methods. Behaviour, 49, 227-267.

BABER, C. (1994). Tools and techniques: The Observer. Applied Ergonomics, 25, 398-399.

Boccia, M. L. (1992, March). Product review: The Observer. Bulletin of the American Society of Primatologists, pp. 6-7.

Boccia, M. L. (1995). Practical computing: The Observer Version 3.0. Practicing Anthropology, 17, 59-61.

Davis, A. J. (1993). The Observer: An integrated software package for behavioural research. Journal of Animal Ecology, 62, 218-219.

DonÁt, P. (1991). Measuring behaviour: The tools and the strategies. Neuroscience \& Biobehavioral Reviews, 15, 447-454.

Farrell, A. D. (1991). Computers and behavioral assessment: Current applications, future possibilities, and obstacles to routine use. $B e-$ havioral Assessment, 13, 159-179.

HiLE, M. G. (1991). Hand-held behavioral observations: The Observer. Behavioral Assessment, 13, 187-196.

Horner, R. H., \& Storey, K. S. (1989). Putting behavioral units back into the stream of behavior: A consumer report. The Behavioral Therapist, 12, 249-251.

Kahng, S. W., \& Iwata, B. A. (1998). Computerized systems for collecting real-time observational data. Journal of Applied Behavior Analysis, 31, 253-261.

KeENE, J, (1994). Software review: The Observer. Behavioural \& Cognitive Psychotherapy, 22, 181-183.

Lazarus, J. (1994). The Observer, Version 3.0. Psychology Software News, 4, 47-48.

LEHNER, P. H. (1996). Handbook of ethological methods (2nd ed.). Cambridge: Cambridge University Press.

Martin, P., \& Bateson, P. (1993). Measuring behaviour: An introductory guide (2nd ed.). Cambridge: Cambridge University Press.

MCPHEE, B. (1992). Musculoskeletal complaints in workers engaged in repetitive work in fixed postures. In M. I. Bullock (Ed.), Ergonomics: The physiotherapist in the workplace. New York: Churchill Livingstone.

Noldus, L. P. J. J. (1991). The Observer: A software system for collection and analysis of observational data. Behavior Research Methods, Instruments, \& Computers, 23, 415-429.

Noldus, L. P. J. J., Van de LoO, E. H. L. M., \& Timmers, P. H. A. (1989). Computers in behavioural research. Nature, 341, 767-768.

PUTZ-ANDERSON, V. (Ed.) (1992). Cumulative trauma disorders: A manual for musculoskeletal diseases of the upper limbs. Bristol, PA: Taylor \& Francis.

Rempel, D. M., Harrison, R. J., \& BARnharT, S. (1992). Work-related cumulative trauma disorders of the upper extremity. Journal of the American Medical Association, 268, 787-788.

Sanderson, P. M., Scott, J. J. P., Johnston, T., Mainzer, J., WataNABE, L. M., \& JAMES, J. M. (1994). MacSHAPA and the enterprise of Exploratory Sequential Data Analysis (ESDA). International Journal of Human-Computer Studies, 41, 633-668.

TAPP, J., \& WALDEN, T. (1993). PROCODER: A professional tape control, coding, and analysis system for behavioral research using videotape. Behavior Research Methods, Instruments, \& Computers, 25, 53-56.

TourTELlot, M. K. (1992). Software review: The Observer. Journal of Insect Behavior, 5, 415-416.

VISSER, M. E. (1993). The Observer, a software package for behavioural observations. Animal Behaviour, 45, 1045.

Vlugt, M. J. van Der, Kruk, M. R., Erp, A. M. M. van, \& Geuze, R. H. (1992). CAMERA: A system for fast and reliable acquisition of multiple ethological records. Behavior Research Methods, Instruments, \& Computers, 24, 147-149.

WAWRA, M. (1994). The Observer 3.0, a software package for behavioural observations. Ethology, 96, 95-96. 


\section{APPENDIX A \\ Description of the Research Design Used in the RSI Case Study}

\section{Experiment Design}

Sampling method: Focal sampling

Independent variables: name of operator, gender, age, workstation, zone, height

Table A1

Behavioral Classes and Elements, With Keyboard Code, Modifier (If Applicable), and Definition for Each Behavioral Element

\begin{tabular}{|c|c|c|c|c|}
\hline Class & Elements & Code & Modifier & Definition \\
\hline \multirow[t]{2}{*}{ Shoulder flexion } & Shoulder flexion & Sfl & Degrees & $\begin{array}{l}\text { Shoulder flexion } \\
\text { from }-45^{\circ} \text { to } 180^{\circ} \\
\text { (upper arm hanging down }=0^{\circ} \text { ) }\end{array}$ \\
\hline & Shoulder no flexion & Snf & & $\begin{array}{l}\text { Shoulder no flexion (upper arm } \\
\text { hanging down, parallel to body) }\end{array}$ \\
\hline \multirow[t]{2}{*}{ Shoulder abduction } & Shoulder abduction & Sab & Degrees & $\begin{array}{l}\text { Shoulder abduction } \\
\text { from } 0^{\circ} \text { to } 180^{\circ}\end{array}$ \\
\hline & Shoulder no abduction & Snb & & $\begin{array}{l}\text { Shoulder no abduction } \\
\text { (upper arm close to body) }\end{array}$ \\
\hline \multirow[t]{2}{*}{ Wrist radial deviation } & $\begin{array}{l}\text { Wrist ulnar deviation } \\
\text { Wrist radial deviation } \\
\text { Wrist nor ulnar nor }\end{array}$ & $\begin{array}{l}\text { Wud } \\
\text { Wrd }\end{array}$ & & $\begin{array}{l}\text { Bending wrist toward little finger } \\
\text { Bending wrist toward thumb }\end{array}$ \\
\hline & radial deviation & Wnr & & Wrist no ulnar or radial deviation \\
\hline \multirow[t]{3}{*}{ Wrist extension } & Wrist flexion & Wfl & & Bending wrist down \\
\hline & $\begin{array}{l}\text { Wrist extension } \\
\text { Wrist nor flexion }\end{array}$ & Wex & & Bending wrist up \\
\hline & nor extension & Wne & & Wrist nor flexion nor extension \\
\hline Wrist supination & $\begin{array}{l}\text { Wrist supination } \\
\text { Wrist pronation }\end{array}$ & $\begin{array}{l}\text { Wsu } \\
\text { Wpr }\end{array}$ & & $\begin{array}{l}\text { Palm up } \\
\text { Palm down }\end{array}$ \\
\hline Elbow flexion & $\begin{array}{l}\text { Elbow flexion } \\
\text { Elbow no flexion }\end{array}$ & $\begin{array}{l}\text { Rfl } \\
\text { Enf }\end{array}$ & Degrees & $\begin{array}{l}\text { Elbow flexion } \\
\text { Lower arm perpendicular } \\
\text { on upper arm }\end{array}$ \\
\hline Hand grip & $\begin{array}{l}\text { Hand power } \\
\text { Hand pinch } \\
\text { Hand other }\end{array}$ & $\begin{array}{l}\text { Hpw } \\
\text { Hpi } \\
\text { Hot }\end{array}$ & $\begin{array}{l}\text { Objects } \\
\text { Objects }\end{array}$ & $\begin{array}{l}\text { Power grip } \\
\text { Pinch grip } \\
\text { Hand nor power nor pinch grip }\end{array}$ \\
\hline Hand activity & $\begin{array}{l}\text { Hand cut } \\
\text { Hand weld } \\
\text { Hands personal care } \\
\text { Hand no activity }\end{array}$ & $\begin{array}{l}\text { Hct } \\
\text { Hwd } \\
\text { Hcr } \\
\text { Hna }\end{array}$ & $\begin{array}{l}\text { Objects } \\
\text { Objects }\end{array}$ & $\begin{array}{l}\text { Cut with pliers } \\
\text { Weld with pliers } \\
\text { Hands personal care } \\
\text { Hand no activity }\end{array}$ \\
\hline Postures & $\begin{array}{l}\text { Stand } \\
\text { Seat slump } \\
\text { Seat upright }\end{array}$ & $\begin{array}{l}\text { Pst } \\
\text { Pss } \\
\text { Psu }\end{array}$ & & $\begin{array}{l}\text { Stand up } \\
\text { Slumping in seat } \\
\text { Sit upright in seat }\end{array}$ \\
\hline Hand location & $\begin{array}{l}\text { Medium } \\
\text { Close } \\
\text { Far }\end{array}$ & $\begin{array}{l}\text { Hme } \\
\mathrm{Hcl} \\
\mathrm{Hnf}\end{array}$ & & $\begin{array}{l}\text { Medium distance } \\
\text { Close distance } \\
\text { Far distance }\end{array}$ \\
\hline Task & $\begin{array}{l}\text { Task begin } \\
\text { Task end }\end{array}$ & $\begin{array}{l}\text { Tbg } \\
\text { Ted }\end{array}$ & $\begin{array}{l}\text { Task number } \\
\text { Task number }\end{array}$ & $\begin{array}{l}\text { Beginning of task } \\
\text { End of task }\end{array}$ \\
\hline
\end{tabular}


APPENDIX A (Continued)

Table A2

Modifier Classes and Elements,

With Code and Definition for Each Element

\begin{tabular}{llll}
\hline \multicolumn{1}{c}{ Class } & \multicolumn{1}{c}{ Elements } & Code & \multicolumn{1}{c}{ Definition } \\
\hline Objects & Plier bend & $\mathrm{pb}$ & Plier to bend wire \\
& Plier cut & $\mathrm{pc}$ & Plier to cut wire \\
& Welding machine & wm & Handling welding machine \\
& Nothing & no & Handling no objects \\
& Work component & wc & Handling work component \\
& +90 & +90 & From $+45^{\circ}$ to $+90^{\circ}$ \\
Degrees & +45 & +45 & From $0^{\circ}$ to $+45^{\circ}$ \\
& -45 & -45 & From $0^{\circ}$ to $-45^{\circ}$ \\
& 180 & 180 & From $135^{\circ}$ to $180^{\circ}$ \\
& 135 & 135 & From $90^{\circ}$ to $135^{\circ}$ \\
& -90 & -90 & From $-45^{\circ}$ to $-90^{\circ}$ \\
Task number & 1 & 1 & Task 1 \\
& 2 & 2 & Task 2 \\
& 3 & 3 & Task 3 \\
\hline
\end{tabular}




\section{TASK1.ODF: Example of a Detailed Observational Data File Generated by the Observer Video-Pro}

This data file resulted in second focal observation.

For meaning of codes, see Appendix A.

\begin{tabular}{|c|c|}
\hline IGNITION.CNF & 0.68 elbowfle,+90 \\
\hline Ignition welding machine & 0.72 shoflex, -45 \\
\hline $05-26-1998$ & 0.72 elbowfle,+45 \\
\hline $00: 00: 13.64$ & 0.72 wrnosupi \\
\hline$\{$ media $\}$ & 0.76 wrulndev \\
\hline MPEG movies & 0.80 wrnexten \\
\hline $\mathrm{d}:$ movies/welding.mpg & 0.84 elbownfl \\
\hline \{indvar\} & 0.92 handpinc, workcomp \\
\hline Patrizia & 0.92 shonofle \\
\hline female & 0.92 wrextens \\
\hline 38 & 1.08 wrnexten \\
\hline Ignition welding machine & 1.12 shoflex, -45 \\
\hline 5 & 1.12 wrnradde \\
\hline 185 & 1.16 shoabduc, +45 \\
\hline$\{$ start $\}$ & 1.16 handothe \\
\hline 0.00 shonofle & 1.20 wrponat \\
\hline 0.00 shoabduc, +90 & 1.28 elbowfle, -45 \\
\hline 0.00 wrulndev & 1.36 shonofle \\
\hline 0.00 wrextens & 1.40 wrraddev \\
\hline 0.00 elbowfle, -90 & 1.40 wrextens \\
\hline 0.00 handpowe,workcomp & 1.48 shoflex, +45 \\
\hline 0.00 wrpronat & 1.76 handpinc,workcomp \\
\hline 0.00 handnoac & 1.92 shonofle \\
\hline 0.00 pseatupr & 1.96 wrnradde \\
\hline 0.00 handfar & 2.00 elbownfl \\
\hline 0.00 taskbegi, 1 & 2.04 shoflex,+45 \\
\hline 0.16 shoabduc, +45 & 2.04 snoabdu \\
\hline 0.24 elbowfle, -45 & 2.12 elbowfle,+45 \\
\hline 0.28 wrnosupi & 2.16 hndmediu \\
\hline 0.36 wrnradde & 2.24 shoabduc, +45 \\
\hline 0.40 elbownfl & 2.36 wrnexten \\
\hline 0.40 wrnexten & 2.40 elbownfl \\
\hline 0.44 hndmediu & 2.44 handpinc, weldmach \\
\hline 0.48 elbowfle,+45 & 2.44 handweld,workcomp \\
\hline 0.48 wrraddev & [section removed] \\
\hline 0.48 wrponat & 10.84 shoabduc, +90 \\
\hline 0.52 shoflex, -45 & 10.92 wrnexten \\
\hline 0.56 hnclose & 10.96 elbowfle, -90 \\
\hline 0.56 snoabdu & 10.96 taskbegi, 2 \\
\hline 0.56 wrextens & $11.0\{$ end $\}$ \\
\hline 0.60 wrnradde & $\{$ notes \\
\hline 0.64 shonofle & \\
\hline
\end{tabular}

(Manuscript received March 23, 1999;

revision accepted for publication October 3, 1999.) 